\title{
Effect of alirocumab on coronary plaque in patients with coronary artery disease assessed by optical coherence tomography
}

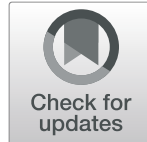

Fei Gao ${ }^{*}$ Zhi Jian Wang, Xiao Teng Ma, Hua Shen, Li Xia Yang and Yu Jie Zhou*

\begin{abstract}
Background: Proprotein convertase subtilisin kexin type 9 (PCSK9) inhibitors have been demonstrated to produce significantly greater reduction in LDL cholesterol levels and cardiovascular events than standard statin therapy. However, evidence on the impact of PCSK9 inhibitors on coronary plaque composition and morphology is limited.

Methods: In this open-label randomized study, eligible patients with intermediate coronary lesions and elevated LDL cholesterol values were randomized to either alirocumab $75 \mathrm{mg}$ Q2W plus statin (atorvastatin $20 \mathrm{mg} /$ day or rosuvastatin $10 \mathrm{mg} /$ day) therapy or standard care. Optical coherence tomography (OCT) assessments for target lesions were obtained at baseline and at 36 weeks of follow-up.

Results: LDL cholesterol levels were significantly decreased in both the alirocumab and standard care arms, whereas the absolute reduction in LDL cholesterol was significantly greater in patients treated with alirocumab $(1.72 \pm 0.51$ vs. $0.96 \pm 0.59, P<0.0001)$. Compared with standard care, the addition of alirocumab to statins was associated with significantly greater increases in minimum fibrous cap thickness (18.0 [10.8-29.2] $\mu \mathrm{m}$ vs 13.2 [7.4$18.6] \mu \mathrm{m} ; P=0.029)$, greater increases in minimum lumen area $\left(0.20[0.10-0.33] \mathrm{mm}^{2}\right.$ vs $0.13[0.12-0.24] \mathrm{mm}^{2} ; P=$ $0.006)$ and a greater diminution in maximum lipid arc (15.1 [7.8-24.5] vs. 8.4 [2.0-10.5]; $P=0.008)$.
\end{abstract}

Conclusions: The addition of alirocumab to statins can not only provide additional LDL cholesterol lowering effects but also have a potential role in promoting a more stable plaque phenotype.

Trial registration: ClinicalTrials.gov Identifier: NCT04851769. Registered 2 Mar 2019.

Keywords: Coronary artery disease, PCSK9 inhibitors, Statins, Coronary plaque, Optical coherence tomography

\section{Introduction}

Low-density lipoprotein (LDL) cholesterol lowering therapy with statins is the cornerstone for effective treatment of coronary artery disease [1, 2]. However, a substantial proportion of patients cannot achieve target LDL cholesterol levels or tolerate effective doses of statin therapy [3, 4]. In fact, markedly increased residual cardiac risks are observed in this population [1]. Proprotein convertase subtilisin kexin type 9 (PCSK9) inhibitors can

\footnotetext{
*Correspondence: fgaomd@163.com; azzyj12@163.com Department of Cardiology, An Zhen Hospital, Capital Medical University, Anzhenli avenue, Chao Yang district, Beijing 100029, China
}

reduce intrahepatic degradation of LDL receptors, which leads to increased hepatic expression of LDL receptors and reduced LDL cholesterol levels [4, 5]. Evidence shows that the addition of PCSK9 inhibitors is associated with significantly greater reductions in LDL cholesterol levels and adverse cardiovascular events compared to statins [5-7]. Therefore, current guidelines recommend the use of PCSK9 inhibitors for patients at high cardiovascular risk who cannot reach target LDL cholesterol levels despite maximally tolerated statins $[1,2]$.

Recently, a series of intravascular ultrasound (IVUS) studies demonstrated that PCSK9 inhibitors in addition 
to statins achieved significantly greater atheroma volume regression than statin monotherapy [8-11]. However, due to the limited spatial resolution, IVUS is unable to evaluate the effects of PCSK9 inhibitors on fibrous cap thickness (FCT), which has been confirmed as an important indicator of plaque vulnerability [12, 13]. Although it has been well established that LDL cholesterol lowering therapy with statins has favorable effects on reducing coronary atheroma burden and increasing fibrous cap thickness $[14,15]$, it remains unclear whether the addition of PCSK9 inhibitors could further improve FCT. Optical coherence tomography (OCT) is currently the gold standard for evaluating the small changes in FCT [16, 17]. Therefore, the aim of this study was to evaluate the effects of PCSK9 inhibitors on fibrous cap thickness by OCT imaging in patients with intermediate coronary lesions.

\section{Methods}

The study is an open-label, single-center, randomized study involving patients with intermediate coronary lesions (50-70\% diameter stenosis). From March 2019 to Jan 2020, all consecutive patients who received coronary angiogram and OCT imaging in An Zhen Hospital (Beijing, China), which is a teaching hospital in which over 15,000 percutaneous coronary intervention procedures are performed each year, were evaluated. Eligible patients included those who were (I) 18-80 years of age, (II) diagnosed with stable coronary artery disease or acute coronary syndrome (ACS) on admission, (III) planned to have clinically indicated coronary angiography and identified wit'h at least one intermediate lesion $(50-70 \%$ diameter stenosis) on de novo coronary arteries, (IV) identified with elevated LDL cholesterol values (LDL cholesterol $\geq 1.81 \mathrm{mmol} / \mathrm{L}$ [ $\geq 70 \mathrm{mg} / \mathrm{dL}]$ for patients with ACS, or $\geq 2.59 \mathrm{mmol} / \mathrm{L}$ [ $\geq 100 \mathrm{mg} / \mathrm{dL}]$ for non-ACS patients) despite taking rosuvastatin $10 \mathrm{mg} /$ day or atorvastatin $20 \mathrm{mg} /$ day for 2-4 weeks or with maximally tolerated statin therapy, and (V) able to provide written, informed consent. The study inclusion and exclusion criteria are listed in Table 1.

The study included a 36-week open-label treatment period (including posttreatment OCT imaging), initiating within 4 weeks of baseline coronary angiogram (Fig. 1). During the open-label treatment period, patients were randomized 1:1 to either the alirocumab arm or the standard care arm. Patients in the alirocumab arm received alirocumab $75 \mathrm{mg}$ Q2W on top of standard statin therapy (atorvastatin $20 \mathrm{mg} /$ day or rosuvastatin 10 $\mathrm{mg}$ /day). The last dose of alirocumab was given at week 34. Patients in the standard care arm continued to receive atorvastatin $20 \mathrm{mg} /$ day or rosuvastatin $10 \mathrm{mg} /$ day. Statin dose escalation or the addition of other concomitant nonstatin lipid-lowering therapies could be considered by the physicians responsible for achieving the target LDL cholesterol levels. Antithrombotic therapy and other concomitant medications were exclusively decided by their responsible physicians. Follow-up coronary angiograms and OCT imaging analyses of the same vessels were carried out at the end of the treatment period in both arms (at week $36 \pm 2$ weeks). Regular medical examinations and laboratory tests were conducted at 4, 12 and 36 weeks. All enrolled patients were monitored and evaluated for medical adherence to lipid lowering therapy, safety and any other adverse events during the study period. LDL cholesterol, HDL

Table 1 Inclusion and Exclusion criteria

\begin{tabular}{|c|c|}
\hline Inclusion criteria & Exclusion criteria \\
\hline $18-80$ years of age & $\begin{array}{l}\text { Known hypersensitivity or contraindications to alirocumab } \\
\text { and/or statin therapy }\end{array}$ \\
\hline Diagnosed as stable coronary artery disease or acute coronary syndrome & $\begin{array}{l}\text { Received balloon angioplasty or stent implantation for } \\
\text { target lesion }\end{array}$ \\
\hline Received OCT imaging measurement & Unable to conduct OCT imaging analysis \\
\hline $\begin{array}{l}\text { LDL cholesterol values } \geq 1.81 \mathrm{mmol} / \mathrm{L} \text { for patients with } \mathrm{ACS} \text { or } \geq 2.59 \mathrm{mmol} / \mathrm{L} \text { for } \\
\text { non-ACS patients despite statin therapy }\end{array}$ & Prior usage of PCSK9 inhibitors \\
\hline $\begin{array}{l}\text { At least one intermediate lesion (50-70\% diameter stenosis) in de novo } \\
\text { coronary arteries }\end{array}$ & $\begin{array}{l}\text { Severe renal dysfunction (creatinine clearance } \\
<30 \mathrm{~mL} / \mathrm{min} \text { ) }\end{array}$ \\
\hline \multirow[t]{6}{*}{ Provided written informed consent } & Severe hepatic dysfunction \\
\hline & Baseline triglyceride $>400 \mathrm{mg} / \mathrm{dl}$ \\
\hline & History of hemorrhagic stroke \\
\hline & Pregnant or breast-feeding women \\
\hline & Life expectancy $<1$ year \\
\hline & $\begin{array}{l}\text { Inappropriate for the study for any reason based on } \\
\text { the investigators' judgement }\end{array}$ \\
\hline
\end{tabular}




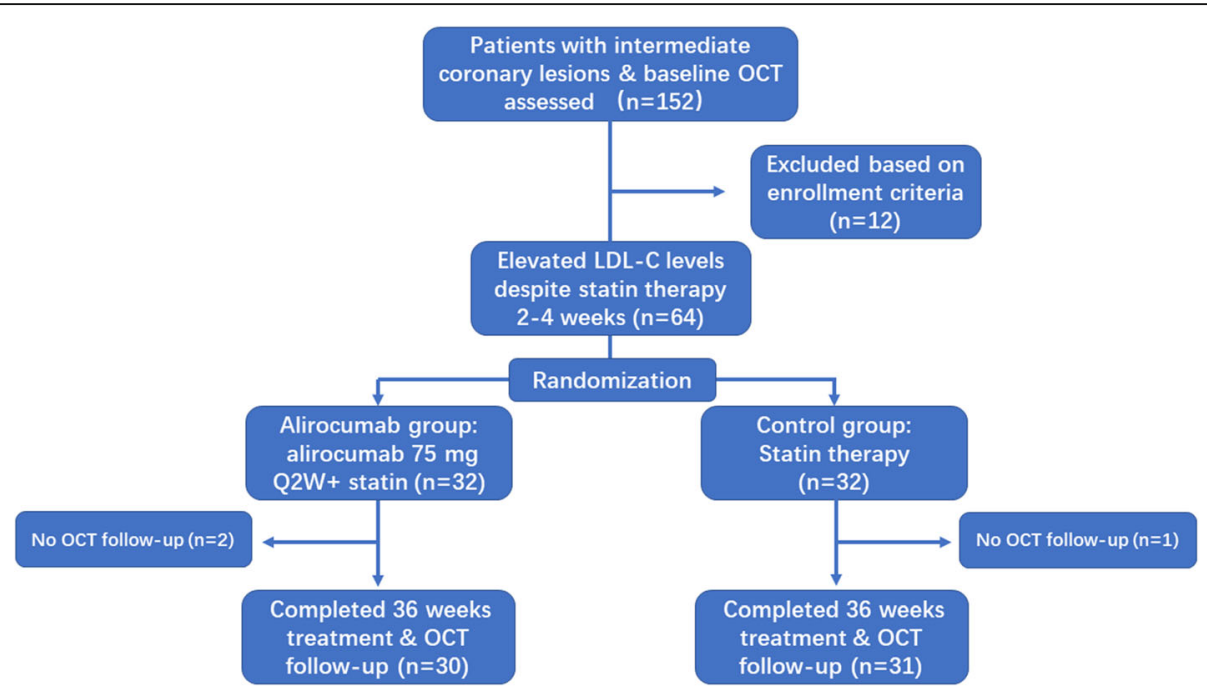

Fig. 1 Study flow

cholesterol, and triglycerides were measured by the central laboratory. LDL cholesterol was calculated according to the Friedewald formula [18]. The study was approved by the local medical ethics committee.

\section{Optical coherence tomography}

OCT images were obtained at baseline and at the $36 \pm 2$-week follow-up. Optical coherence tomography imaging systems (Optis or Ilumien Imaging System ${ }^{\mathrm{Tm}}$, Abbott Vascular, USA) were used. Testing on contrast injection was required to ensure a complete wash-out of the vessel. The entire length of the target lesions (including $5 \mathrm{~mm}$ proximal and distal segments) was evaluated. All imaging analyses were performed by independent investigators who were blinded to the study protocol. Target lesions between baseline and follow-up OCT were matched and compared based on the distance from the landmarks (e.g., calcifications and branches). Calibration was required before image analysis. Values of minimum lumen area, minimum FCT, and maximum lipid arc were measured. The target plaque was characterized using previously established criteria [19].

\section{Study endpoints}

The primary endpoint of the study was the OCT derived absolute changes in minimum fibrous cap thickness between baseline and follow-up. Secondary endpoints included the absolute changes in minimum lumen area between baseline and follow-up, as well as the absolute changes in maximum lipid arc. Minimum fibrous cap thickness was defined as the smallest FCT in the three candidate frames selected by manual screening. The maximum lipid arc was defined as the largest lipid arc from the center of the lumen. The minimum lumen area was defined as the smallest lumen area in the target lesion calculated by automated measurements and manual corrections.

In addition, the incidence rates of major adverse cardiac events (defined as the composite outcome of death, myocardial infarction, and ischemia-driven target lesion revascularization) and treatment related adverse reactions during the follow-up period were recorded. Myocardial infarction was defined according to the fourth universal definition of myocardial infarction [20]. Ischemia-driven target lesion revascularization was defined as reintervention driven by anginal symptoms and significant angiographic stenosis $(>70 \%$ diameter stenosis).

\section{Statistical analysis}

Continuous variables are reported as the means \pm standard deviations or median (interquartile ranges). Categorical variables are presented as counts and percentages. Continuous variables between the two groups were compared by the Mann-Whitney $U$ test. Comparisons of continuous variables between baseline and follow-up were performed by the Wilcoxon signed rank test. Comparisons of categorical variables were performed by the Fisher's exact test. A two-tailed test $P$ value $<0.05$ was considered as statistically significant. The SPSS Statistics 25.0 package was used.

\section{Results}

A total of 61 eligible patients (31 patients in the standard care arm and 30 patients in the alirocumab arm) with complete clinical and OCT imaging follow-up were analyzed (Fig. 1). Nearly half of the patients (15/31) in the standard care arm received ezetimibe and statin combination therapy. The baseline and procedural characteristics of the two groups are listed in Table 2. Of note, 
Table 2 Baseline characteristics

\begin{tabular}{|c|c|c|}
\hline & $\begin{array}{l}\text { Standard of care } \\
(N=31)\end{array}$ & $\begin{array}{l}\text { Alirocumab } \\
(N=30)\end{array}$ \\
\hline Age, yrs & $61.3 \pm 9.9$ & $61.3 \pm 8.9$ \\
\hline Male & $74.2(23)$ & $66.7(20)$ \\
\hline Diabetes & $25.8(8)$ & $23.3(7)$ \\
\hline Current smoker & $25.8(8)$ & $30(9)$ \\
\hline Hypertension & $61.3(19)$ & $56.7(17)$ \\
\hline Prior Ml & $9.7(3)$ & $13.3(4)$ \\
\hline Prior stroke & $3.2(1)$ & $10.0(3)$ \\
\hline ACS & $41.9(13)$ & $36.7(11)$ \\
\hline Antiplatelet & $100(31)$ & $100(30)$ \\
\hline Beta-blocker & $90.3(28)$ & $93.3(28)$ \\
\hline ACEI/ARB & $64.5(20)$ & $60.0(18)$ \\
\hline Chronic statin before enrollment & $32.3(10)$ & $26.7(8)$ \\
\hline \multicolumn{3}{|l|}{ Imaged artery } \\
\hline Left anterior desending & $41.9(13)$ & $43.3(13)$ \\
\hline Left circumflex & $22.6(7)$ & 26.7 (8) \\
\hline Right coronary & $32.2(10)$ & $30.0(9)$ \\
\hline Others & $3.2(1)$ & 0 \\
\hline
\end{tabular}

ACS acute coronary syndrome, $M I$ myocardial infarction, $A C E I / A R B$ angiotensinconverting enzyme inhibitors/angiotensin receptor blockers

patients were predominantly male and had a high percentage of guideline recommended medical therapies in both groups. All the participants were prescribed antiplatelet therapy, and approximately $90 \%$ of them were treated with beta blockers.

Biochemical measures throughout the study are summarized in Table 3. At baseline, no significant differences were observed between the standard care arm and the alirocumab arm. At week 36, LDL cholesterol levels were significantly decreased in both groups compared with baseline, from $3.18 \mathrm{mmol} / \mathrm{L}$ to $2.22 \mathrm{mmol} / \mathrm{L}(P<$ $0.0001)$ in the standard care arm and from $3.04 \mathrm{mmol} / \mathrm{L}$ to $1.32 \mathrm{mmol} / \mathrm{L}$ in the alirocumab arm $(P<0.0001)$. However, the absolute changes in LDL cholesterol levels were significantly higher in patients treated with alirocumab $(1.72 \pm 0.51$ vs. $0.96 \pm 0.59, P<0.0001)$. In addition, patients in alirocumab arm demonstrated favorable changes in triglyceride levels, but the differences were not significant. C-reactive protein (CRP) levels decreased in both groups, but no significant difference was observed between the groups.

OCT-derived baseline and follow-up parameters are listed in Table 4. Significantly greater increases in the changes in minimum FCT (18.0 [10.8-29.2] $\mu \mathrm{m}$ vs. 13.2 [7.4-18.6] $\mu \mathrm{m} ; P=0.029)$ and the changes of minimum lumen area $\left(0.20[0.10-0.33] \mathrm{mm}^{2}\right.$ vs. $0.13 \quad[0.12-$ $\left.0.24 \mathrm{~mm}^{2} ; P=0.006\right)$ were observed in the alirocumab group compared to the standard care group. Similarly, the absolute changes in the maximum lipid arc were also significantly greater in the alirocumab group than in the standard care group (15.1 [7.8-24.5] vs. 8.4 [2.0-10.5]; $P=0.008$ ). Additionally, patients in the alirocumab arm demonstrated a trend of greater but not statistically significant reduction in the percentage of thin-cap fibroatheroma (TCFA) compared to those in the standard care arm $(3.3 \%$ vs. $16.1 \% ; P=0.09)$.

No death or myocardial infarction event was recorded in either the alirocumab or standard care arm (Table 5). However, 1 patient suffered from ischemia driven target lesion revascularization in the standard care arm, but not in the alirocumab arm. The incidence of treatmentrelated adverse reactions was similar in both groups. Nasopharyngitis (standard care: 1 patient; alirocumab: 2 patients) was the most common reaction. Two (6.7\%) patients in the alirocumab group experienced local injection-site reactions. All the treatment-related adverse reactions found in this study were recorded as mild in intensity, and all the participants were tolerated following their treatment plan.

\section{Discussion}

The results of our study indicated that the addition of alirocumab was associated with a significantly greater reduction in LDL cholesterol levels, a greater increase in FCT, and a greater diminution in maximum lipid arc, compared with standard lipid lowering therapy.

The impact of lipid lowering therapy on atheroma plaque morphology was initially established in statin trials [21]. Coronary plaque regression can be achieved when the decrease in LDL cholesterol levels exceeds $50 \%$ due to the treatment of statins [22]. However, our previous epidemiological study indicated that large numbers of patients cannot achieve sufficient LDL cholesterol reductions despite treatment with statin therapy [3]. PCSK9 inhibitors are novel pharmacologic agents, and it has been shown that the addition of PCSK9 inhibitors to statins can further reduce LDL cholesterol levels by 43 to $64 \%$ [23]. However, evidence regarding the effect of PCSK9 inhibitors on atheroma plaque stability is limited. The ODYSSEY J-IVUS trials showed that the addition of alirocumab to statins resulted in a numerical greater reduction in total atheroma volume, but it did not attain statistical significance due to the limited sample size [10]. Conversely, the GLAGOV trial reported a significant reduction in atheroma volume in patients treated with evolocumab for 76 weeks [8]. However, the GLAGOV trial showed that the addition of evolocumab did not produce differential changes in plaque composition by IVUS assessment compared to statin monotherapy. Although the addition of PCSK9 inhibitors was shown to reduce atheroma volume in these two studies, there is a gap of evidence regarding the impact of PCSK9 inhibition on other vulnerable plaque features, 
Table 3 Biochemical parameters

\begin{tabular}{|c|c|c|c|}
\hline & $\begin{array}{l}\text { Standard of care } \\
(N=31)\end{array}$ & $\begin{array}{l}\text { Alirocumab } \\
(N=30)\end{array}$ & $P$ Value \\
\hline \multicolumn{4}{|l|}{ LDL cholesterol, mmol/L } \\
\hline Baseline & $3.18 \pm 0.97$ & $3.04 \pm 0.78$ & - \\
\hline After 36 weeks treatment & $2.22 \pm 0.69$ & $1.32 \pm 0.39$ & $<0.0001$ \\
\hline Changes from baseline & $-0.96 \pm 0.59$ & $-1.72 \pm 0.51$ & $<0.0001$ \\
\hline \multicolumn{4}{|l|}{ HDL cholesterol, mmol/L } \\
\hline Baseline & $1.30 \pm 0.41$ & $1.41 \pm 0.61$ & - \\
\hline After 36 weeks treatment & $1.38 \pm 0.43$ & $1.48 \pm 0.47$ & 0.35 \\
\hline Changes from baseline & $0.08 \pm 0.36$ & $0.07 \pm 0.38$ & 0.74 \\
\hline \multicolumn{4}{|l|}{ Triglycerides, mmol/L } \\
\hline Baseline & 1.56 (1.19 to 2.38$)$ & 1.84 (1.19 to 2.56$)$ & - \\
\hline After 36 weeks treatment & 1.53 (1.09 to 2.26$)$ & 1.54 (1.00 to 2.09$)$ & 0.68 \\
\hline Changes from baseline & -0.05 (0.64 to 1.42$)$ & $-0.29(-0.96$ to 0.35$)$ & 0.077 \\
\hline \multicolumn{4}{|l|}{ CRP, mg/L } \\
\hline Baseline & 1.62 (0.90 to 3.00$)$ & 1.69 (0.75 to 3.37$)$ & - \\
\hline After 36 weeks treatment & 1.10 (0.89 to 2.50$)$ & 1.59 (0.92 to 2.61$)$ & 0.64 \\
\hline Changes from baseline & $0.54(-0.46$ to 1.34$)$ & $0.12(-0.74$ to 1.08$)$ & 0.50 \\
\hline
\end{tabular}

$C R P C$-reactive protein, $L D L$ low-density lipoprotein, $H D L$ high-density lipoprotein

such as fibrous cap thickness. OCT imaging analysis, which has 10 times greater resolution than IVUS, is an ideal imaging modality to assess fibrous cap thickness of coronary plaque $[17,24]$. A recent retrospective, observational OCT study revealed that evolocumab provided a greater increase in FCT in patients with recent acute coronary syndrome than statin monotherapy [25]. To date, there is only one randomized study evaluating the effects of PCSK9 inhibitors on plaque morphology by OCT - the ALTAIR study [26]. It enrolled 24 patients randomized to either alirocumab or statins (rosuvastatin $10 \mathrm{mg} / \mathrm{d}$ ). It also showed a significantly greater increase in fibrous cap thickness in the alirocumab group than in the statin group. However, in the current study nearly half of the patients in the standard care arm received ezetimibe and statin combination therapy. It was close

Table 4 OCT -derived study endpoints

\begin{tabular}{|c|c|c|c|}
\hline & $\begin{array}{l}\text { Standard of care } \\
(N=31)\end{array}$ & $\begin{array}{l}\text { Alirocumab } \\
(N=30)\end{array}$ & $P$ Value \\
\hline \multicolumn{4}{|c|}{ Minimum fibrous cap thickness, um } \\
\hline Baseline & 116.4 (90.1 to 136.2$)$ & $126.0(87.5$ to 145.5$)$ & 0.44 \\
\hline After 36 weeks treatment & $124.2(98.2$ to 144.3$)$ & 144.0 (111.5 to 151.8$)$ & 0.049 \\
\hline Changes from baseline & $13.2(7.4$ to 18.6$)$ & $18.0(10.8$ to 29.2$)$ & 0.029 \\
\hline \multicolumn{4}{|l|}{ Maximum lipid arc, degree } \\
\hline Baseline & $110.9(90.2$ to 132.4$)$ & 109.6 (89.8 to 130.0$)$ & 0.53 \\
\hline After 36 weeks treatment & $102.2(87.0$ to 123.1$)$ & 93.5 (77.5 to 108.1$)$ & 0.19 \\
\hline Changes from baseline & $-8.4(-2.0$ to -10.5$)$ & $-15.1(-7.8$ to -24.5$)$ & 0.008 \\
\hline \multicolumn{4}{|l|}{ Minimum lumen area, $\mathrm{mm}^{2}$} \\
\hline Baseline & 2.47 (2.20 to 2.74$)$ & $2.32(2.07$ to 2.63$)$ & 0.22 \\
\hline After 36 weeks treatment & 2.60 (2.19 to 2.90$)$ & 2.57 (2.27 to 2.90$)$ & 0.77 \\
\hline Changes from baseline & $0.13(0.12$ to 0.24$)$ & 0.20 (0.10 to 0.33$)$ & 0.006 \\
\hline \multicolumn{4}{|l|}{ TCFA, \%(n) } \\
\hline Baseline & $25.8(8)$ & $20.0(6)$ & 0.59 \\
\hline After 36 weeks treatment & $16.1(5)$ & $3.3(1)$ & 0.09 \\
\hline
\end{tabular}


Table 5 Clinical events

\begin{tabular}{lll}
\hline & $\begin{array}{l}\text { Standard of care } \\
(\mathbf{N}=\mathbf{3 1})\end{array}$ & $\begin{array}{l}\text { Alirocumab } \\
(\mathbf{N}=\mathbf{3 0})\end{array}$ \\
\hline Adverse cardiac events & 0 & 0 \\
Cardiac death & 0 & 0 \\
Myocardial infarction & 1 & 0 \\
$\begin{array}{l}\text { Ischemia driven target lesion } \\
\text { revascularization, }\end{array}$ & \\
Treatment-related adverse events & 1 & 2 \\
Nasopharyngitis & 1 & 2 \\
Injection-site reaction & 0 & 1 \\
Back pain & 1 & 1 \\
Transaminase elevation & & \\
\hline
\end{tabular}

to real-world clinical practice since the recent guidelines also recommended adding an ezetimibe before initiating PCSK9 inhibitors for patients with elevated LDL cholesterol levels. The results of this study were generally consistent with previous studies and demonstrated a significantly greater increase in minimum lumen area in the alirocumab arm assessed by OCT imaging. In addition, the alirocumab arm was associated with a significantly greater increase in FCT and a greater reduction in maximum lipid arc compared with the standard care arm. The current results indicated that the addition of alirocumab can not only provide profound LDL cholesterol lowering effects but also have a potential role in improving the stability of the plaque.

Although statins have demonstrated a significant CRP lowering effect, and the degree of CRP lowering was correlated with the extent of plaque regression $[27,28]$ and cardiovascular event risk reduction [29], it remains controversial whether PCSK9 inhibitors have similar effects on CRP levels. A recent Mendelian randomization study found strong associations of decreased PCSK9 concentrations and increased CRP levels [30]. In this study, no incremental reductions in CRP levels were observed in patients treated with alirocumab. However, the study might be underpowered to detect the differences in CRP between the groups; thus, the differences need to be further evaluated in large studies. However, the study results suggested that the favorable effects of alirocumab on the plaque phenotype were independent of CRP changes. A previous meta-analysis also indicated that the reduction in coronary atherosclerosis observed with nonstatin lipid-lowering therapy was attributed to the degree of LDL cholesterol lowering [31]. Therefore, it seems reasonable to believe that the effects of PCSK9 on coronary plaque might be mediated by LDL cholesterol lowering Fig. 2.

\section{Study strength and limitations}

The current trial is the first randomized OCT imaging trial to show the superiority of alirocumab over standard lipid lowering therapy (including highintensity statin and ezetimibe combination therapy) on plaque modification in patients with intermediate coronary lesions. However, there are several potential limitations to this study. The first major limitation is the relatively short treatment duration; therefore, the long-term effects of PCSK9 inhibitors on plaque, as well as their clinical prognosis cannot be evaluated. The second limitation is the open nature of this study. The person who conducted the OCT imaging scans and analyses were unaware of the patients' allocation. However, the patients and treating physicians in this study were unblinded, which might influence the treatment benefits. The third limitation is that the
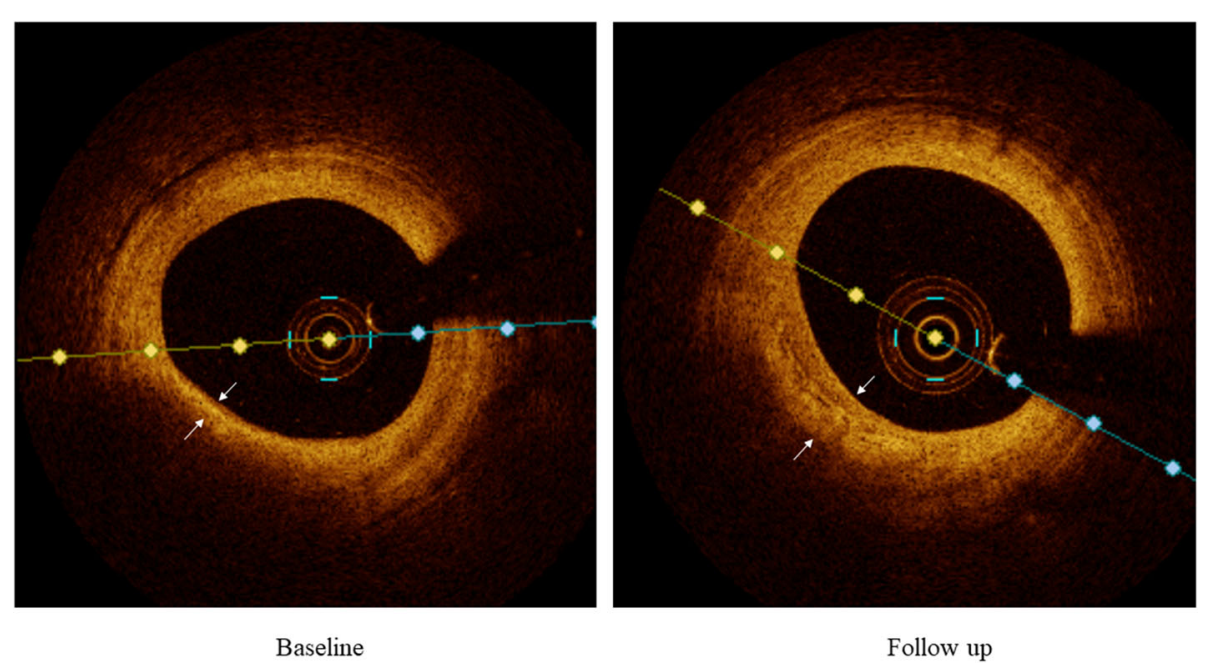

Fig. 2 Representative OCT imaging. Changes in fibrous cap thickness (white arrows) between baseline and follow-up in a patient with alirocumab 
study did not record and compare medical adherence except for lipid lowering agents. Since recent evidence showed that PCSK9 inhibitors could positively affect treatment adherence and patients' quality of life [32, 33], it may introduce potential bias into the study. Another important limitation is that there is no compelling evidence demonstrating a direct link between the increase in OCT-derived fibrous-cap thickness and the improvement in cardiovascular prognosis. However, a series of pathological studies certified that FCT is a major determinant of vulnerable coronary plaque $[12,34]$. Furthermore, it is well acknowledged that OCT-defined thin-cap fibroatheroma is correlated with vulnerable plaque characters identified by other imaging techniques [35], all of which have a strong link to future adverse clinical events [23, 36]. Therefore, to date, the increase in fibrous cap thickness has been considered a representation of coronary plaque stabilization [37-40].

\section{Conclusions}

Among patients who cannot achieve LDL cholesterol targets despite standard lipid lowering therapy, the addition of alirocumab can not only provide a greater reduction in LDL cholesterol, but also have a favorable effect on improving the vulnerability of the plaque. Further studies are needed to clarify the clinical implications of these results measured by OCT.

\section{Abbreviations}

LDL: Low-density lipoprotein; PCSK9: Proprotein convertase subtilisin kexin type 9; IVUS: Intravascular ultrasound; OCT: Optical coherence tomography; FCT: Fibrous cap thickness; ACS: Acute coronary syndrome; CRP: C-reactive protein; MI: Myocardial infarction; ACEl/ARB: Angiotensin-converting enzyme inhibitors/angiotensin receptor blockers; TCFA: Thin-cap fibroatheroma

\section{Acknowledgements}

We thank the entire study team for their participation and contributions.

\section{Authors' contributions}

$F$ Gao and $Y$ J Zhou were responsible for the study design and management. $\mathrm{H}$ Shen were responsible for the data resources and integrity. Z J Wang and X T Ma conducted the OCT Imaging analysis. L X Yang helped with data management and statistical analysis. F Gao analyzed the data and drafted the manuscript. The authors read and approved the final manuscript.

\section{Funding}

The study was funded by the Capital's Funds for Health Improvement and Research.

\section{Availability of data and materials}

The datasets used and/or analyzed during the current study are available from the corresponding author on reasonable request.

\section{Declarations}

\section{Ethics approval and consent to participate}

The study protocol was approved by Ethics Committee of Beijing Anzhen Hospital, Capital university and all participants provided written informed consent. The study was performed in accordance with the principles of the Declaration of Helsinki.
Consent for publication

Not applicable.

\section{Competing interests}

None.

Received: 5 July 2021 Accepted: 23 August 2021

Published online: 12 September 2021

\section{References}

1. Arnett DK, Blumenthal RS, Albert MA, Buroker AB, Goldberger ZD, Hahn EJ, et al. 2019 ACC/AHA guideline on the primary prevention of cardiovascular disease: a report of the American College of Cardiology/American Heart Association task force on clinical practice guidelines. Circulation. 2019; 140(11):e596-646. https://doi.org/10.1161/CIR.0000000000000678.

2. Michos ED, McEvoy JW, Blumenthal RS. Lipid management for the prevention of atherosclerotic cardiovascular disease. N Engl J Med. 2019; 381(16):1557-67. https://doi.org/10.1056/NEJMra1806939.

3. Gao F, Zhou YJ, Hu DY, Zhao YX, Liu YY, Wang ZJ, et al. Contemporary management and attainment of cholesterol targets for patients with Dyslipidemia in China results of a Chinese Society of Cardiology National Survey -- REALITY-CHINA SURVEY. PLoS One. 2013;8(4):e47681. https://doi. org/10.1371/journal.pone.0047681.

4. Nicholls SJ, Nissen SE, Prati F, Windecker S, Kataoka Y, Puri R, et al. Assessing the impact of PCSK9 inhibition on coronary plaque phenotype with optical coherence tomography: rationale and design of the randomized, placebocontrolled HUYGENS study. Cardiovasc Diagn Ther. 2021;11(1):120-9. https:// doi.org/10.21037/cdt-20-684

5. Robinson JG, Farnier M, Krempf M, Bergeron J, LuC G, Averna M, et al. Efficacy and safety of alirocumab in reducing lipids and cardiovascular events. N Engl J Med. 2015;372:1489-99. https://doi.org/10.1056/NEJMoa1 501031

6. Sabatine MS, Giugliano RP, Keech AC, Honarpour N, Wiviott SD, Murphy SA, et al. Evolocumab and clinical outcomes in patients with cardiovascular disease. N Engl J Med. 2017;376:1713-22. https://doi.org/10.1056/NEJMoa1 615664

7. Schwartz GG, Steg PG, Szarek M, Bhatt DL, Bittner VA, Diaz R, et al. Alirocumab and cardiovascular outcomes after acute coronary syndrome. N Engl J Med. 2018;379:2097-107. https://doi.org/10.1056/NEJMoa1801174.

8. Nicholls SJ, Puri R, Anderson T, Ballantyne CM, Cho L, Kastelein JJP, et al. Effect of Evolocumab on coronary plaque composition. J Am Coll Cardiol. 2018;72:2012-21. https://doi.org/10.1016/j.jacc.2018.06.078.

9. Nicholls SJ, Puri R, Anderson T, Ballantyne CM, Cho L, Kastelein JJ, et al. Effect of evolocumab on progression of coronary disease in statin-treated patients: the GLAGOV randomized clinical trial. JAMA. 2016;316:2373-84. https://doi.org/10.1001/jama.2016.16951.

10. Ako J, Hibi K, Tsujita K, Hiro T, Morino Y, Kozuma K, et al. Effect of Alirocumab on coronary atheroma volume in Japanese patients with acute coronary syndrome - the ODYSSEY J-IVUS trial. Circ J. 2019:83:2025-33. https://doi.org/10.1253/circj.CJ-19-0412.

11. Gragnano F, Calabrò P. Role of dual lipid-lowering therapy in coronary atherosclerosis regression: evidence from recent studies. Atherosclerosis 2018;269:219-28. https://doi.org/10.1016/j.atherosclerosis.2018.01.012.

12. Virmani R, Kolodgie FD, Burke AP, Farb A, Schwartz SM. Lessons from sudden coronary death: a comprehensive morphological classification scheme for atherosclerotic lesions. Arterioscler Thromb Vasc Biol. 2000;20: 1262-75. https://doi.org/10.1161/01.atv.20.5.1262.

13. Kolodgie FD, Burke AP, Farb A, Gold HK, Yuan J, Narula J, et al. The thin-cap fibroatheroma: a type of vulnerable plaque: the major precursor lesion to acute coronary syndromes. Curr Opin Cardiol. 2001;16:285-92. https://doi. org/10.1097/00001573-200109000-00006.

14. Komukai K, Kubo T, Kitabata H, Matsuo Y, Ozaki Y, Takarada S, et al. Effect of atorvastatin therapy on fibrous cap thickness in coronary atherosclerotic plaque as assessed by optical coherence tomography: the EASY-FIT study. J Am Coll Cardiol. 2014;64:2207-17. https://doi.org/1 0.1016/j.jacc.2014.08.045

15. Kini A, Vengrenyuk $Y$, Shameer $K$, Maehara A, Purushothaman $M$, Yoshimura $T$, et al. Intracoronary imaging, cholesterol efflux, and Transcriptomes after intensive statin treatment: the YELLOW II study. J Am Coll Cardiol. 2017; 69(6):628-40. https://doi.org/10.1016/j.jacc.2016.10.029. 
16. Kim Y, Johnson TW, Akasaka T, Jeong MH. The role of optical coherence tomography in the setting of acute myocardial infarction. J Cardiol. 2018;72: 186-92. https://doi.org/10.1016/j.jjcc.2018.03.004.

17. Kume T, Akasaka T, Kawamoto T, Okura H, Watanabe N, Toyota E, et al. Measurement of the thickness of the fibrous cap by optical coherence tomography. Am Heart J. 2006;152:755. e1-4. https://doi.org/10.1016/j.ahj.2 006.06.030.

18. Friedewald WT, Levy RI, Fredrickson DS. Estimation of the concentration of low-density lipoprotein cholesterol in plasma, without use of the preparative ultracentrifuge. Clin Chem. 1972;18:499-502.

19. Tearney GJ, Regar E, Akasaka T, Adriaenssens T, Barlis P, Bezerra HG, et al. Consensus standards for acquisition, measurement, and reporting of intravas- cular optical coherence tomography studies: a report from the international working Group for Intravascular Optical Coherence Tomography Standardiza- tion and validation. J Am Coll Cardiol. 2012;59: 1058-72. https://doi.org/10.1016/j.jacc.2011.09.079.

20. Thygesen K, Alpert JS, Jaffe AS, Chaitman BR, Bax JJ, Morrow DA, et al. Executive group on behalf of the joint European Society of Cardiology (ESC)/American College of Cardiology (ACC)/American Heart Association (AHA)/world heart federation (WHF) task force for the universal definition of myocardial infarction. J Am Coll Cardiol. 2018;72(18):2231-64. https://doi. org/10.1016/j.jacc.2018.08.1038.

21. Nicholls SJ, Ballantyne CM, Barter PJ, Chapman MJ, Erbel RM, Libby P, et al. Effect of two intensive statin regimens on progression of coronary disease. N Engl J Med. 2011;365:2078-87. https://doi.org/10.1056/NEJMoa1110874.

22. Nissen SE, Tuzcu EM, Schoenhagen P, Brown BG, Ganz P, Vogel RA, et al. Effect of intensive compared with moderate lipid-lowering therapy on progression of coronary atherosclerosis: a randomized controlled trial. JAMA. 2004;291:1071-80. https://doi.org/10.1001/jama.291.9.1071.

23. Del Pinto R, Grassi D, Properzi G, Desideri G, Ferri C. Low density lipoprotein (LDL) cholesterol as a causal role for atherosclerotic disease: potential role of PCSK9 inhibitors. High Blood Press Cardiovasc Prev. 2019;26:199-207. https://doi.org/10.1007/s40292-019-00323-7.

24. Johnson TW, Räber L, di Mario C, Bourantas C, Jia H, Mattesini A, et al. Clinical use of intracoronary imaging. Part 2: acute coronary syndromes, ambiguous coronary angiography findings, and guiding interventional decision-making: an expert consensus document of the European Association of Percutaneous Cardiovascular Interventions. Eur Heart J. 2019; 40(31):2566-84. https://doi.org/10.1093/eurheartj/ehz332.

25. Yano H, Horinaka S, Ishimitsu T. Effect of evolocumab therapy on coronary fibrous cap thickness assessed by optical coherence tomography in patients with acute coronary syndrome. J Cardiol. 2020;75(3):289-95. https://doi. org/10.1016/j.jjcc.2019.08.002.

26. Sugizaki Y, Otake H, Kawamori H, Toba T, Nagano Y, Tsukiyama Y, et al. Adding Alirocumab to Rosuvastatin helps reduce the vulnerability of thincap Fibroatheroma: an ALTAIR trial report. JACC Cardiovasc Imaging. 2020; 13(6):1452-4. https://doi.org/10.1016/j.jcmg.2020.01.021

27. Nissen SE, Tuzcu EM, Schoenhagen P, Crowe T, Sasiela WJ, Tsai J, et al. Statin therapy, LDL cholesterol, C-reactive protein, and coronary artery disease. N Engl J Med. 2005;352:29-38. https://doi.org/10.1056/NEJMoa042 000.

28. Puri R, Nissen SE, Libby P, Shao M, Ballantyne CM, Barter PJ, et al. C-reactive protein, but not low-density lipoprotein cholesterol levels, associate with coronary atheroma regression and cardiovascular events after maximally intensive statin therapy. Circulation. 2013;128:2395-403. https://doi.org/10.11 61/CIRCULATIONAHA.113.004243.

29. Ridker PM, Cannon CP, Morrow D, Rifai N, Rose LM, McCabe CH, et al. Creactive protein levels and outcomes after statin therapy. $\mathrm{N}$ Engl J Med. 2005;352:20-8. https://doi.org/10.1056/NEJMoa042378.

30. Schmidt AF, Hunt NB, Gordillo-Marañón M, Charoen P, Drenos F, et al. Cholesteryl ester transfer protein as a drug target for cardiovascular disease. medRxiv. 2020. https://doi.org/10.1101/2020.09.07.20189571.

31. Masson W, Lobo M, Siniawski D, Molinero G, Masson G, Huerín M, et al. Role of non-statin lipid-lowering therapy in coronary atherosclerosis regression: a meta-analysis and meta-regression. Lipids Health Dis. 2020;19(1):111. https:// doi.org/10.1186/s12944-020-01297-5.

32. Cesaro A, Gragnano F, Fimiani F, Moscarella E, Diana V, Pariggiano I, et al. Impact of PCSK9 inhibitors on the quality of life of patients at high cardiovascular risk. Eur J Prev Cardiol. 2020;27(5):556-8. https://doi.org/10.11 77/2047487319839179
33. Gragnano F, Natale F, Concilio C, Fimiani F, Cesaro A, Sperlongano S, et al Adherence to proprotein convertase subtilisin/kexin 9 inhibitors in high cardiovascular risk patients: an Italian single-center experience. J Cardiovasc Med (Hagerstown). 2018;19(2):75-7. https://doi.org/10.2459/JCM. 0000000000000611.

34. Buja LM, Willerson JT. Role of inflammation in coronary plaque disruption. Circulation. 1994;89:503-5. https://doi.org/10.1161/01.cir.89.1.503.

35. Sawada T, Shite J, Garcia-Garcia HM, Shinke T, Watanabe S, Otake H, et al. Feasibility of combined use of intravascular ultrasound radiofrequency data analysis and optical coherence tomography for detecting thin-cap fibroatheroma. Eur Heart J. 2008;29:1136-46. https://doi.org/10.1093/eurhea rtj/ehn132.

36. Stone GW, Maehara A, Lansky AJ, de Bruyne B, Cristea E, Mintz GS, et al. A prospective natural-history study of coronary atherosclerosis. N Engl J Med. 2011;364:226-35. https://doi.org/10.1056/NEJMoa1002358.

37. Nishiguchi T, Kubo T, Tanimoto T, Ino Y, Matsuo Y, Yamano T, et al. Effect of early pitavastatin therapy on coronary fibrous-cap thickness assessed by optical coherence tomography in patients with acute coronary syndrome: the ESCORT study. JACC Cardiovasc Imaging. 2018;11:829-38. https://doi. org/10.1016/j.jcmg.2017.07.011.

38. Zanchin C, Koskinas KC, Ueki Y, Losdat S, Häner JD, Bär S, et al. Effects of the PCSK9 antibody alirocumab on coronary atherosclerosis in patients with acute myocardial infarction: a serial, multivessel, intravascular ultrasound, near-infrared spectroscopy and optical coherence tomography imaging study-rationale and design of the PACMAN-AMI trial. Am Heart J. 2021;238: 33-44. https://doi.org/10.1016/j.ahj.2021.04.006.

39. Min JK, Chandrashekhar Y, Narula J. The immediate effects of statins on coronary atherosclerosis. JACC Cardiovasc Imaging. 2018;11:839-41. https:// doi.org/10.1016/j.jcmg.2017.08.008.

40. Otake H, Sugizaki Y, Toba T, Nagano Y, Tsukiyama Y, Yanaka Kl, et al. Efficacy of alirocumab for reducing plaque vulnerability: study protocol for ALTAIR, a randomized controlled trial in Japanese patients with coronary artery disease receiving rosuvastatin. J Cardiol. 2019;73(3):228-32. https://doi.org/1 0.1016/j.jjcc.2018.11.012.

\section{Publisher's Note}

Springer Nature remains neutral with regard to jurisdictional claims in published maps and institutional affiliations.
Ready to submit your research? Choose BMC and benefit from:

- fast, convenient online submission

- thorough peer review by experienced researchers in your field

- rapid publication on acceptance

- support for research data, including large and complex data types

- gold Open Access which fosters wider collaboration and increased citations

- maximum visibility for your research: over $100 \mathrm{M}$ website views per year

At BMC, research is always in progress.

Learn more biomedcentral.com/submissions 